\title{
Dynastic Entrepreneurship, Entry, and Non-Compete Enforcement
}

\author{
James Rauch
}

CESIFO WORKING PAPER NO. 5370

CATEGORY 11: INDUSTRIAL ORGANISATION

MAY 2015

An electronic version of the paper may be downloaded

- from the SSRN website: Www.SSRN.com

- from the RePEc website: Www.RePEc.org

- from the CESifo website: www.CESifo-group.org/wp 


\title{
Dynastic Entrepreneurship, Entry, and Non-Compete Enforcement
}

\begin{abstract}
We investigate entry in a dynastic entrepreneurship (overlapping generations) environment created by employee spinoffs. Without finance constraints, enforcement of non-compete agreements unambiguously improves social welfare outcomes, and even increases the rate of spinoffs from original firms. Indeed, if employers have all the bargaining power vis-à-vis their employees, optimal entry of original firms and all subsequent employee spinoffs is achieved, despite the fact that the original firm can only negotiate with the first spinoff. However, if employees are unable to buy out their non-compete contracts, enforcement of these agreements shuts down socially profitable spinoff firms. Non-enforcement sacrifices entry of original firms that would be marginally profitable in the absence of employee spinoffs, but otherwise clearly improves social welfare outcomes over enforcement in the presence of finance constraints.
\end{abstract}

JEL-Code: K120, L260.

Keywords: entrepreneurship, entry, finance constraints, non-competes, overlapping generations, spinoffs.

\author{
James Rauch \\ Department of Economics \\ University of California San Diego \\ 9500 Gilman Drive \\ USA - 92093-0508 La Jolla CA \\ jrauch@ucsd.edu \\ (econweb.ucsd.edu/_jrauch/)
}

March 29, 2015

My thanks to Ayal Chen-Zion and Lindsay Rickey for outstanding research assistance and to Joel Watson for many helpful discussions. I am responsible for any errors. 


\section{Introduction}

Employee spinoffs are widely recognized to be a major mode of entrepreneurship in high-tech manufacturing (Klepper and Sleeper 2005, Franco and Filson 2006). Recognition of their importance in the rest of the economy has been growing (Phillips 2002, Eriksson and Kuhn 2006, Hvide 2009, Muendler, Rauch, and Tocoian 2012). Muendler, Rauch, and Tocoian were the first to tabulate employee spinoffs for an entire economy: depending on definition, employee spinoffs account for between one-sixth and one-third of all new formal private sector firms in Brazil during the period 1995-2001. They found that, regardless of definition, employee spinoffs perform better on average than new firms without (identifiable) parents: their sizes at entry are larger and their survival rates are higher.

Employee spinoffs often go into direct competition with their parent firms. This is natural since they build on knowledge of technology, clients/markets, and suppliers acquired during employment at their parents (Klepper and Sleeper 2005, Franco and Filson 2006, Muendler and Rauch 2014). Parents therefore have an incentive to prevent spinoffs through enforcement of restrictive employment clauses such as non-compete covenants (hereafter simply called non-competes). Where these are not enforceable, employers may try to restrict spinoff opportunities to family members to at least keep the employee spinoff profits in the family (Shieh 1992).

A tentative consensus has formed in the literature in favor of not enforcing non-competes (Acs, Glaeser, Litan, Fleming, Goetz, Kerr, Klepper, Rosenthal, Sorenson, and Strange 2008). Yet this consensus is based on narrow empirical evidence, mainly for high-tech industry, where circulation/spillover of ideas through employee mobility is especially important (Fallick, Fleishman, and Rebitzer 2006, Gilson 1999, Marx, Strumsky, and Fleming 2009). A broadly-based counterargument is that enforcement of non-competes gives employers greater incentives to invest in their employees. It can be objected, however, that non-enforcement gives employees greater incentives to innovate, or more generally make investments of their own (Motta and Roende 2002, Baccara and Razin 2009, Kräkel and Sliwka 2009). Garmaise (2011) finds evidence that increased incentives for employees to invest in their general human capital empirically dominate reduced incentives by employers to invest in their employees' firm-specific human capital.

This paper evaluates a very different counter-argument: insofar as employee spinoffs hurt their parents, failure to enforce non-competes may reduce entry by parent firms. This in turn may reduce the very spinoff entrepreneurship that the non-enforcement policy was supposed to encourage. I 
will investigate entry in a dynastic entrepreneurship (overlapping-generations) world. I find that, if employees can buy out their non-compete contracts, enforcement of non-compete agreements unambiguously increases entry of both original (parent) firms and all subsequent spinoffs. Indeed, if employers have all the bargaining power vis-à-vis their employees, socially optimal entry of original firms and all subsequent spinoffs is achieved, despite the fact that the original firm can only negotiate with the first spinoff. However, if employees are finance-constrained and hence unable to buy out their non-compete contracts, enforcement of these agreements prevents startup of socially profitable spinoff firms. Non-enforcement sacrifices entry of original firms that would be marginally profitable in the absence of employee spinoffs, but otherwise clearly improves social welfare outcomes over enforcement in the presence of employee finance constraints by facilitating entry of socially profitable spinoff firms.

Franco and Mitchell (2008) also investigate theoretically the impact of non-compete enforcement on entry of both parent and spinoff firms. My model differs from theirs in several important respects. First, as already mentioned I recognize that spinoff entrepreneurship implies a dynastic environment: like any other firm, a spinoff can have a spinoff. The "family tree" spawned by Fairchild Semiconductor is a famous example. ${ }^{1}$ Second, agents in my model can differ by their (commonly known) profitability of entry (driven by differences in their startup costs), rather than by their (privately known) ability to learn the parent firm technology. Third, I analyze the case in which finance constraints on employee-entrepreneurs prevent them from buying out their contracts with their employers, without which enforcement of non-competes does not pose a barrier to (socially beneficial) spinoffs (Rauch and Watson 2015). Interestingly, it is my results with finance constraints that are consistent with Franco and Mitchell: enforcement leads to more entry of original firms and eliminates spinoffs. Without finance constraints, however, enforcement does better than non-enforcement in all respects, unlike in Franco and Mitchell: there is more entry of both original firms and spinoffs. ${ }^{2}$

Without finance constraints, the importance of a dynastic (overlapping generations) rather than two-period analysis in my framework becomes especially clear. Enforcement of non-competes

\footnotetext{
${ }^{1}$ Systematic investigation of spinoffs of spinoffs is hampered by the fact that the time dimension of a typical firmlevel panel data set is short relative to the length of a typical spinoff "generation." Klepper and Sleeper (2005) find that the highest rate of spinoffs in the laser industry is from firms aged 11 to 15 . The average age of parents at birth of (first) spinoff in the Brazilian data set used by Muendler, Rauch, and Tocoian (2012) is 15 years, and the median age is nine years.

${ }^{2}$ It follows that whether enforcement increases or reduces spinoffs indirectly reveals the salience of finance constraints. I discuss this further in my Conclusions.
} 
is predicted to increase the rate of spinoffs from original entrants relative to non-enforcement, whereas in a two-period setting enforcement would have no effect on this rate. This positive prediction has corresponding normative consequences: enforcement improves social welfare relative to non-enforcement because of both increased original firm entry and increased rate of spinoffs, rather than only because of the former as would be the case in a two-period analysis. The dynastic model also brings out an interesting contrast with the patent literature, specifically Bessen and Maskin (2009). In their "sequential" model, original innovation, subsequent imitation, and patent protection play roles similar to original entry, spinoff entry, and non-compete enforcement in my model. Eliminating patent protection can make both the original innovator and subsequent imitator better off in their model, whereas elimination of non-compete enforcement always hurts the original firm in my model. In my model the gap between the non-enforcement outcome and the social optimum widens in the dynastic analysis relative to a two-period analysis, whereas it narrows in their model for the sequential relative to the static case.

I lay out the basics of my model in the next section of this paper. In section 3 I consider equilibria and the social welfare outcomes they generate when enforcement of non-compete agreements is impossible. In the following section I consider equilibria and social welfare when non-competes can be enforced, maintaining the assumption of no finance constraints. Finally, I add employee finance constraints to the environment with non-compete enforcement in section 5. The results for sections 3, 4, and 5 are presented in parallel. Propositions 3.1, 4.1, and 5.1 specify the equilibria that prevail following entry of the original firm under the assumptions of lack of non-compete enforcement, non-compete enforcement without finance constraints, and non-compete enforcement with finance constraints, respectively. Propositions 3.2 - 5.2 work backward from Propositions 3.1 - 5.1 to determine the conditions under which the original firm enters. Propositions $3.3-5.3$ build on Propositions 3.1 - 5.1 and 3.2 - 5.2 to find the conditions under which the social optimum is and is not achieved. I discuss empirical evidence and policy implications in the concluding section.

\section{The model}

We consider parent and spinoff entry in a stationary, overlapping generations environment. At the beginning of time (period 0), a firm enters that we will call the original firm. In period 1, an employee spinoff from the original firm may enter. In period 2 , the original firm exits, and 
a second generation spinoff firm may enter. The model continues in this way indefinitely, with each entrant surviving for two periods and generating a potential spinoff in its second period of operation. It follows that, starting in period 1, any entrant is a spinoff, and any incumbent firm is a potential parent. Also starting in period 1, if entry fails to occur in a period the line of firms dies out at the end of that period. ${ }^{3}$

We can also specify the timing of firm actions within any given period. An entering firm sinks costs at the beginning of the period. After entering, the new firm hires labor, produces, and earns profits during the period. At the end of the period one of its employees, selected at random, gets an idea for a spinoff firm. This employee can enter by sinking costs at the beginning of the next period. Like an entering firm, an incumbent firm hires labor, produces, and earns profits during the period. Unlike an entering firm, an incumbent firm exits at the end of the period.

Finally, we assume that if the potential entrant is a spinoff, the employee informs his employer of his intention to resign and start a new firm, at which point employer and employee try to reach an agreement. They bargain under complete information regarding profits and sunk costs. If they agree, any compensating transfers are made immediately. The subject of the bargaining and especially the threat points in the event of disagreement will be influenced by the legal environment and will be specified below.

The labor market is frictionless in the sense that, if the employer and employee separate, the employer can costlessly replace him, and the employee can also costlessly find new employment if he does not found a spinoff firm. Whether the employee separates from the incumbent firm to found his own firm or to be employed elsewhere, the value of the firm-specific human capital he accumulated through his experience at the incumbent firm (not through a costly investment by the firm) is lost to it. The payoff to the employee of alternative employment is normalized to zero. We follow Franco and Mitchell (2008, p. 592) by assuming that this market wage is what every employee earns during the first period of his employment. ${ }^{4}$

\footnotetext{
${ }^{3}$ Dunne, Roberts, and Samuelson (1988) find (Table 11) that the exit rate for new U.S. manufacturing firms after only five years ranges between 57 and 64 percent, depending on entry cohort.

${ }^{4}$ Our approach does not allow for the possibility, explored in Franco and Filson (2006), that parent firms could capture the entire values of employee spinoffs through payment of below-market wages to their employees. Even setting aside the possibility of employee finance constraints (which we take up in section 5 below), such an equilibrium may not obtain in the real world. For example, employees can differ in their propensities to found spinoff firms. If, as seems reasonable, these propensities are private information, there may not exist a separating equilibrium in which employees with high propensities accept lower wages than employees with low propensities, particularly if the former are in the minority. Employees with high propensities will have incentives to report low propensities, and the cost to an employer of distorting the contract for the majority of workers so as to make its refusal incentive compatible
} 
Now focus on a given period in which a spinoff has entered, and consider the interaction between the parent and spinoff in that period. If the presence of the spinoff does not reduce the profits of the incumbent in that period, this presence cannot deter parent entry, making this case uninteresting for our analysis. When the presence of the spinoff reduces incumbent profits in the period, joint profits may be higher or lower than incumbent profits without the spinoff. Higher is the natural outcome to consider when the parent and spinoff produce varieties of goods or services that are imperfect substitutes and thus attract a higher collective proportion of consumer expenditure. Higher joint profits can be derived, for example, in a model with CES utility and Bertrand competition. Lower joint profits seem natural if the parent and spinoff produce perfect substitutes, and would be the outcome if, for example, they engage in Cournot competition. Our analysis is qualitatively unaffected by which case prevails. ${ }^{5}$

To facilitate welfare analysis in our dynastic setting, we will not model labor or product markets explicitly. We therefore measure the contributions of firms to social welfare solely by their profits. This greatly simplifies the analysis of policy below.

We will use $\pi$ to denote the profits of a firm in any given period. Specifically, we let $\pi_{T}$ denote the profits of an incumbent firm when the employer (firm) and employee stay together, $\pi_{S}$ denote the profits of a spinoff entrant, and $\pi_{P}$ denote the profits of a parent firm, i.e., an incumbent firm in competition with a spinoff. When the employee separates from an incumbent firm, the loss of the firm-specific human capital of this experienced employee reduces the incumbent's profits by $h$. By definition, the employee has separated from a parent firm, so we can write $\pi_{P} \equiv \pi_{P T}-h$, where $\pi_{P T}$ equals the hypothetical profits an incumbent firm would earn in competition with a spinoff if it were still together with the employee. In contrast, an incumbent firm that is not a parent may earn $\pi_{T}$ or $\pi_{T}-h$, depending on whether or not the employee has separated. Finally, we denote by $\pi_{0}$ the profits of the original firm in its first period of operation.

Following the discussion above, we assume $\pi_{T}>\pi_{P T}$ or $\pi_{T}-h>\pi_{P}$. It would also be reasonable to assume that old, experienced firms earn greater profits than young, inexperienced firms, so that $\pi_{P}>\pi_{S}$ and $\pi_{T}>\pi_{0}$, but we do not impose these restrictions.

We denote by $K_{0}$ and $K_{S}$ the costs sunk at entry by the original firm and by all subsequent

for a minority may be too high for him to offer a separate contract directed at the latter, a phenomenon known as "non-responsiveness" in the literature (see, e.g., Laffont and Martimort 2001, section 2.11.2).

${ }^{5}$ It might seem that efficient bargaining between employer and employee would always eliminate spinoffs when joint profits are lower, but this conclusion would not take into account the fact that the spinoff continues to earn profits in the future after the parent has exited. 
entrants (spinoffs), respectively. Empirically, we expect $K_{S}<K_{0}$, but we do not impose this restriction. A spinoff entrepreneur should have the advantage of having already learned on the job, and thus needs to invest less time in developing his business idea, should make fewer mistakes in setting up his business, etc. In each of Figures 3.2, 4.2, and 5 below, we place $K_{0}$ on the horizontal axis and $K_{S}$ on the vertical axis, and the reader can imagine a $45^{\circ}$ line below which lies the more empirically relevant parameter space.

Our notation for profits and costs lacks time subscripts, reflecting the stationary environment of our model. This stationary environment facilitates a simple computation of the maximum possible contribution to social welfare (maximum discounted sum of total profits less entry costs) resulting from entry of an original firm:

Proposition 2. The maximum contribution to social welfare generated by entry of an original firm is given by $\pi_{0}+\delta\left(\pi_{P}+\pi_{S}-K_{S}\right) /(1-\delta)-K_{0}$ if $K_{S}<\pi_{P}+\pi_{S}-(1-\delta) \pi_{T}$ and by $\pi_{0}+\delta \pi_{T}-K_{0}$ otherwise.

Proof. Entry of an original firm necessarily yields $\pi_{0}-K_{0}$ in period 0 . In period 1 , if the employer and employee stay together profits equal $\pi_{T}$ in that period and zero in every subsequent period. Spinoff entry in period 1 yields $\pi_{P}+\pi_{S}-K_{S}$ and an identical choice between entry and no entry in period 2. Thus if spinoff entry is best for society in period 1 it must also be best for society in period 2 , and in every subsequent period as well. The maximum contribution to social welfare generated by entry of an original firm is therefore given by either $\pi_{0}+\delta \pi_{T}-K_{0}$ or $\pi_{0}+\sum_{t=1}^{\infty} \delta^{t}\left(\pi_{P}+\pi_{S}-K_{S}\right)-K_{0}=\pi_{0}+\delta\left(\pi_{P}+\pi_{S}-K_{S}\right) /(1-\delta)-K_{0}$. Finally, the inequality $\pi_{0}+\delta\left(\pi_{P}+\pi_{S}-K_{S}\right) /(1-\delta)-K_{0}>\pi_{0}+\delta \pi_{T}-K_{0}$ reduces to $K_{S}<\pi_{P}+\pi_{S}-(1-\delta) \pi_{T}$.

Proposition 2 establishes the standard to which the equilibria in the following three sections will be compared.

\section{Equilibria and social welfare without non-compete enforcement}

In this section we consider equilibria and the social welfare outcomes they generate when enforcement of non-compete agreements is impossible. The timing of the model without non- 
compete enforcement is shown in Figure 3.1. ${ }^{6}$ At the beginning of period 1 the employer and the employee with the idea for a spinoff firm negotiate over whether or not they will stay together. In an abuse of notation, in Figure 3.1 the employer is denoted by $P$ (for parent) and the employee is denoted by $S$ (for spinoff), even though these labels only apply if the employee founds a spinoff firm. If the employer and employee agree to stay together there will be a transfer $\tau$ between them. ${ }^{7}$ Either party can unilaterally compel separation (disagreement). If they separate (fail to agree), then the employee has a choice as to whether to found a spinoff firm or take a job with another firm. In a parallel abuse of notation, the continuation value of the employee who founds a spinoff is denoted by $v_{P}$, even though the employee does not become a parent in the next period in every equilibrium of the game. The timing of period 1 repeats itself indefinitely in future periods; only the identities of the employer and employee change, with the employee in each period taking over the role of employer in the next period.

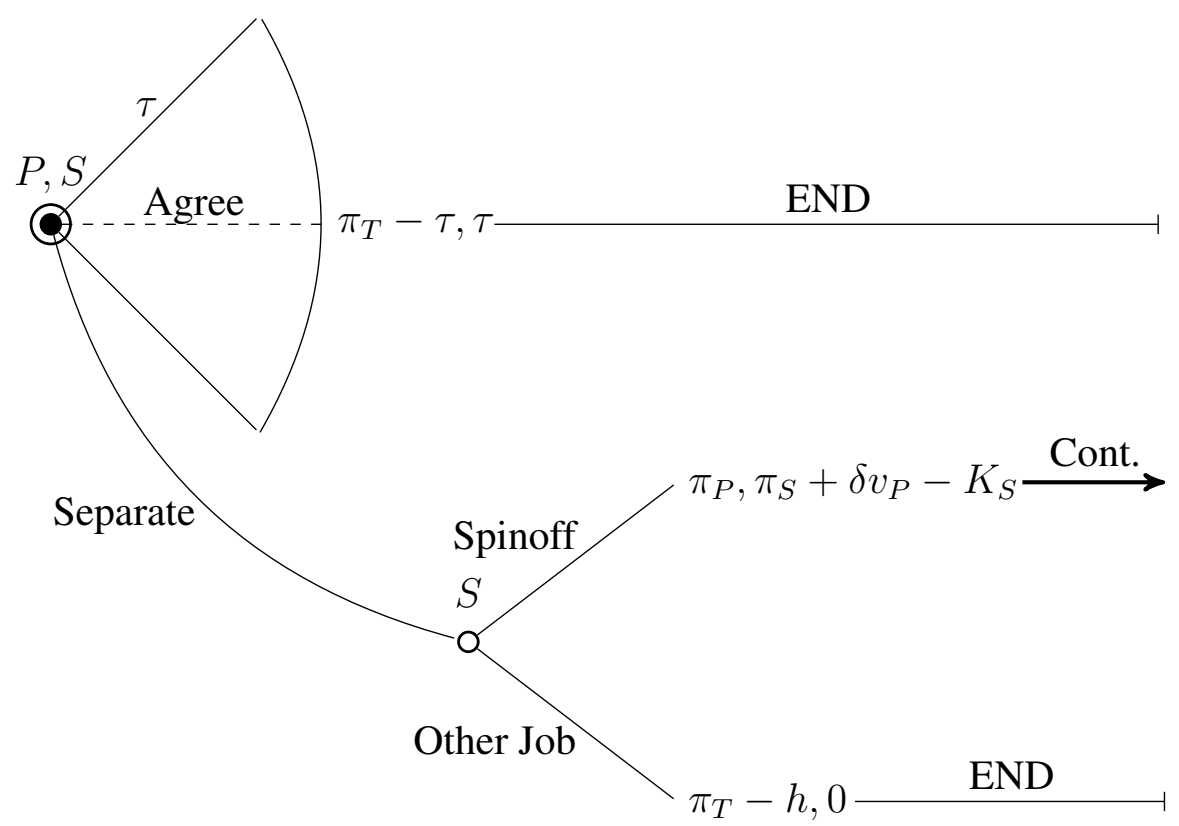

Figure 3.1: One period of the extensive form without non-compete enforcement

We will search for Markov perfect equilibria of the game described by our model. The Markov assumption is a weak one in our setting because, although the game has a history in every period

\footnotetext{
${ }^{6}$ This figure follows the conventions for extensive-form representation used in Watson (2013).

${ }^{7}$ The employer also negotiates with any other employees who acquired bargaining power in the form of firmspecific human capital, but do not have ideas for spinoff firms. We assume that bargaining is unrelated across employees. It is then easily shown that the outcome of these negotiations will always be to stay together. The profit expressions $\pi_{T}$ and $\pi_{P}$ are net of the resulting transfers.
} 
following period zero, in no period do the agents have a history of play with each other. Moreover, in no period does the employer have a history of play with other employees, nor does the employee have a history of play with other employers.

We will show that, in an environment without enforcement of non-compete contracts, there exist two Markov perfect equilibria. In the spinoff equilibrium, the two parties always separate and the employee always founds a spinoff firm. In the no-spinoff equilibrium, the two parties always agree to stay together.

We first establish the threat points of the parties in the spinoff equilibrium. If the employee founds a spinoff firm when the two parties separate, his continuation value $v_{P}$ in the next period is the profit of a parent firm, because one of his employees will have founded a spinoff. If the employee takes another job, his continuation value is zero. After separation, therefore, the employee compares $\pi_{S}+\delta \pi_{P}-K_{S}$ to zero, where $\delta$ denotes the discount rate. The threat point of the employee is then $\pi_{S}+\delta \pi_{P}-K_{S}, K_{S}<\pi_{S}+\delta \pi_{P}$, and zero otherwise. It follows that the threat point of the employer is $\pi_{P}, K_{S}<\pi_{S}+\delta \pi_{P}$, and $\pi_{T}-h$ otherwise.

Computation of the threat points of the parties in the no-spinoff equilibrium is more involved. If the employee founds a spinoff firm when the parties separate, the threat point of the employer is $\pi_{P}$ as before. The continuation value for the employee $v_{P}$ is now the payoff to an incumbent firm that has agreed to stay together with its own employee. Since there is no spinoff in this equilibrium, we denote this continuation value by $v_{N S}$. We have $v_{N S}=\pi_{P}+(1-\lambda)\left(\pi_{T}-\right.$ $\pi_{P}-\pi_{S}-\delta v_{N S}+K_{S}$ ), where $\lambda$ and $1-\lambda$ are the weights in the generalized Nash bargaining solution assigned to an employee and an employer, respectively. We can solve this equation to obtain $v_{N S}=\left[\lambda \pi_{P}+(1-\lambda)\left(\pi_{T}-\pi_{S}+K_{S}\right)\right] /[1+(1-\lambda) \delta]$. The threat point of the employee if he founds a spinoff firm when the parties separate is then $\pi_{S}+\delta v_{N S}-K_{S}$. On the other hand, the threat point of the employee when he takes another job is zero, and the threat point of the employer in this case is $\pi_{T}-h$.

Using this information, we are able to prove the following in the Appendix:

Proposition 3.1. Consider an environment without enforcement of non-compete contracts. Assume entry of the original firm in period 0. Given $K_{S}<\left(\pi_{P}-\pi_{T}\right)+\pi_{S}+\delta \pi_{P}$, a unique Markov perfect equilibrium exists in which there is spinoff entry in period 1 and every subsequent period. Given $K_{S} \geq\left(\pi_{P}-\pi_{T}\right)+\pi_{S}+\delta \pi_{P}$, a unique Markov perfect equilibrium exists in which the employer and employee agree to stay together in period 1 (and would agree to stay together in 
every subsequent period if the game continued).

Proposition 3.1 shows that the spinoff and no-spinoff equilibria obtain for a mutually exclusive and exhaustive partition of the possible values of $K_{S}$. As one would expect, low values of spinoff startup costs lead to the spinoff equilibrium and high values lead to the no-spinoff equilibrium.

Using Proposition 3.1, we can work backwards to the entry decision of the original firm. When the spinoff equilibrium obtains, the original firm anticipates earning $\pi_{0}+\delta \pi_{P}-K_{0}$. When the no-spinoff equilibrium obtains, the original firm anticipates earning $\pi_{0}+\delta v_{N S}-K_{0}$, where $v_{N S}=\left[\lambda \pi_{P}+(1-\lambda)\left(\pi_{T}-\pi_{S}+K_{S}\right)\right] /[1+(1-\lambda) \delta]$ if $K_{S}<\pi_{S}+\delta\left[\pi_{T}-\lambda\left(\pi_{T}-\pi_{P}\right)\right]$, and $\pi_{T}-\lambda h$ otherwise. We thus have ${ }^{8}$

Proposition 3.2. When the spinoff equilibrium obtains, the original firm enters if and only if $\pi_{0}+$ $\delta \pi_{P}>K_{0}$. When the no-spinoff equilibrium obtains, the original firm enters if and only if $\pi_{0}+\delta\left[\lambda \pi_{P}+(1-\lambda)\left(\pi_{T}-\pi_{S}+K_{S}\right)\right] /[1+(1-\lambda) \delta]>K_{0}$, when $K_{S}<\pi_{S}+\delta\left[\pi_{T}-\lambda\left(\pi_{T}-\pi_{P}\right)\right]$, or $\pi_{0}+\delta\left(\pi_{T}-\lambda h\right)>K_{0}$, when $K_{S} \geq \pi_{S}+\delta\left[\pi_{T}-\lambda\left(\pi_{T}-\pi_{P}\right)\right]$.

Figure 3.2 shows the regions of $K_{0}, K_{S}$ space in which the spinoff equilibrium, no-spinoff equilibrium, or neither obtains. The figure is drawn under the assumption that $\left(\pi_{P}-\pi_{T}\right)+\pi_{S}+$ $\delta \pi_{P}>0$. A sufficient condition for this inequality to hold is that the joint profits of the parent and spinoff in any period exceed the profits the incumbent would receive if there were no spinoff and the employer and employee stayed together. We do not consider values of $K_{0}$ for which it is infeasible for entry of the original firm to generate benefits for society. This boundary in the figure is drawn using Proposition 2.

Clearly the social optimum is not achieved when the original firm does not enter even though it is feasible for its entry to generate benefits for society. When the original firm does enter, the spinoff equilibrium yields the discounted sum of profits $\pi_{0}+\delta\left(\pi_{P}+\pi_{S}-K_{S}\right) /(1-\delta)-K_{0}$ and the no-spinoff equilibrium yields the discounted sum of profits $\pi_{0}+\delta \pi_{T}-K_{0}$. Proposition 3.3 then follows from a comparison of Propositions 3.1 and 3.2 with Proposition 2:

Proposition 3.3. When the spinoff equilibrium obtains, the social optimum is achieved. When the no-spinoff equilibrium obtains, the social optimum is achieved when $K_{S} \geq \pi_{P}+\pi_{S}-(1-\delta) \pi_{T}$, but not for $\pi_{P}+\pi_{S}-\pi_{T}+\delta \pi_{P} \leq K_{S}<\pi_{P}+\pi_{S}-(1-\delta) \pi_{T}$, when the social optimum would be

\footnotetext{
${ }^{8}$ If the employee is able to commit to a course of action upon separation as described in the Appendix footnote, we would replace the bounds for $K_{S}$ that divide the cases when the no-spinoff equilibrium obtains with the bounds that divide cases (a) and (b) specified in the Appendix footnote.
} 
achieved if there were spinoff entry. When the original firm does not enter and $K_{0}<\pi_{0}+\delta \pi_{T}$ for $K_{S}>\pi_{P}+\pi_{S}-(1-\delta) \pi_{T}$ or $K_{0}<\pi_{0}+\delta\left(\pi_{P}+\pi_{S}-K_{S}\right) /(1-\delta)$ for $K_{S} \leq \pi_{P}+\pi_{S}-(1-\delta) \pi_{T}$, the social optimum is not achieved.

Xninoff Equilibrium $\triangle$ No-Spinoff Equilibrium $\square$ Social Optimum achieved

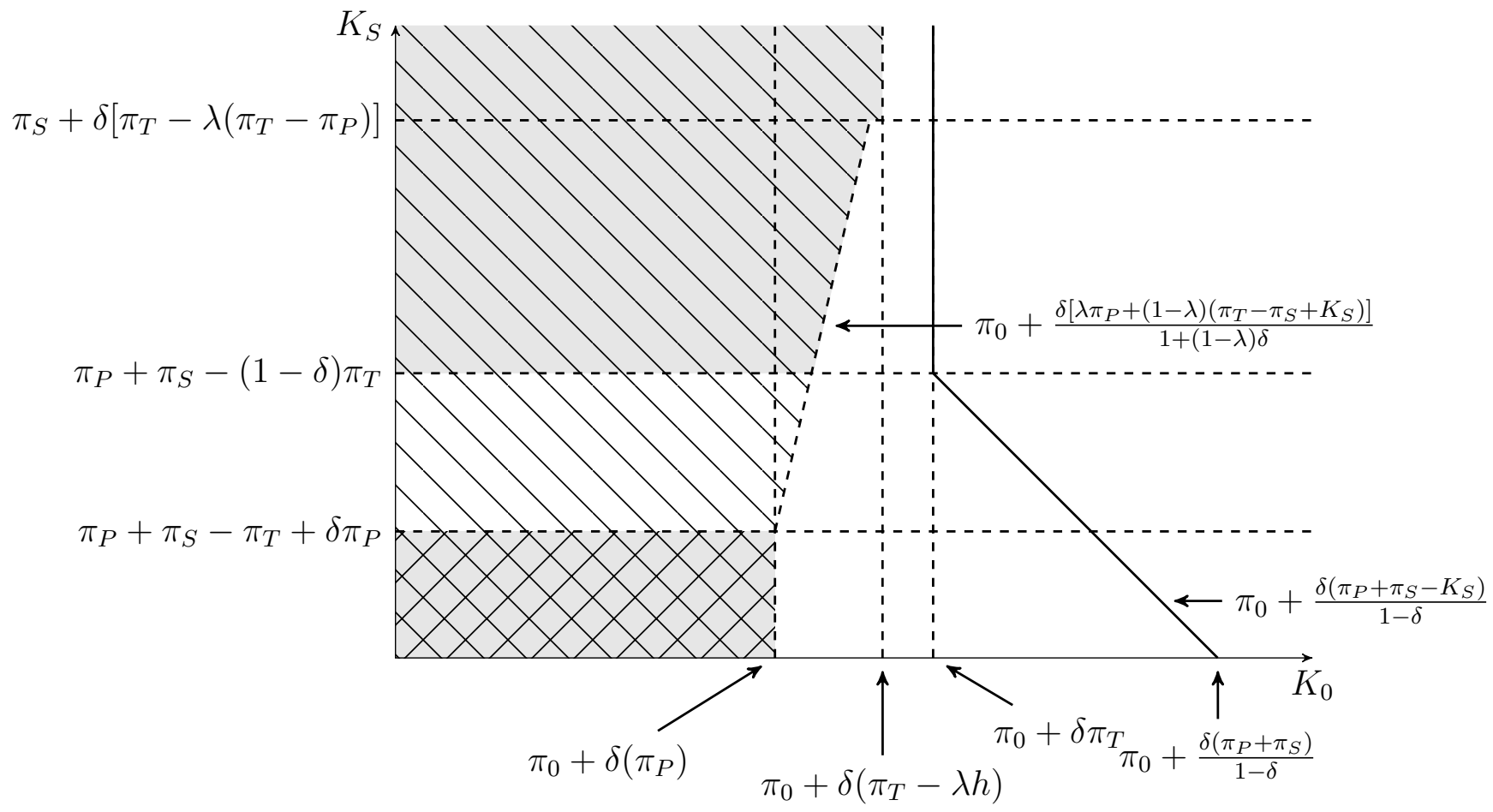

Figure 3.2: Equilibria and social optimum without enforcement of non-compete contracts

Propositions 3.2 and 3.3 are illustrated in Figure 3.2. We see from Figure 3.2 that an original firm fails to enter when it would be socially profitable for it to do so when its profits in the absence of spinoffs would be low or negative. This occurs because the lack of non-compete enforcement leaves the original firm with no means of extracting profits from the spinoff firms that would not exist without its entry. ${ }^{9}$ Ironically, the same problem arises for spinoffs themselves when their profitability is low, because they are unable when they become parents to extract profits from subsequent spinoffs.

\footnotetext{
${ }^{9}$ The firm could ask each of its workers to post a bond that would be forfeit if he founds a spinoff. However, it is hard to see why a court would enforce payment of this bond if it does not enforce non-compete agreements.
} 
We conclude this section by noting that there is legitimate cause for concern that the threat of spinoff entry deters parent (original) firm entry when the latter is socially profitable. In a world without employee spinoffs, it is clear that the original firm should enter when $\pi_{0}+\delta \pi_{T}-K_{0}>0$, yet it may not because entry or negotiation is the best response of its employee with an idea for a new firm, which decreases the original firm's expected profits.

\section{Equilibria and social welfare with non-compete enforcement and no finance constraints}

We now add to our model the possibility that an incumbent firm will block entry of a spinoff firm by petitioning a court to enforce a non-compete agreement that the potential spinoff entrepreneur has signed. (We assume that firms are able to compel employees to sign such agreements as a condition of being hired.) We therefore amend our specification of the nature and timing of employer and employee actions. The employer and employee now negotiate over whether or not they will stay together and, if not, whether they will renegotiate the employee's contract to release him from the non-compete agreement. If they reach an agreement there will be an immediate transfer between them. If they fail to agree, then as before they separate and the employee has a choice as to whether to found a spinoff firm or take a job with another firm. If the employee goes ahead with his plan to found a spinoff firm and sinks $K_{S}$, the employer files suit to block operation of his business. ${ }^{10}$ The payoff to the employee is then $-K_{S}$.

The timing of the model with non-compete enforcement is shown in Figure 4.1, which uses the same notation and conventions as Figure 3.1. It is clear from the bottom of the figure that, when the employer $(P)$ and the employee $(S)$ separate, the employee will choose to take a job with another firm rather than found a spinoff. The separation branch therefore reduces to the payoffs $\pi_{T}-h, 0$ for the employer and employee, respectively, which therefore become their threat points in negotiations. At the top of Figure 4.1 we see that the employer and employee can either agree to stay together, in which case the game ends, or agree to release the employee from his non-compete agreement, ${ }^{11}$ in which case the employee founds a spinoff firm and the game continues in the next

\footnotetext{
${ }^{10}$ The employer may incur court costs. As long as these are less than the loss in profits $\pi_{T}-h-\pi_{P}$ the incumbent firm would suffer as a result of the spinoff, the employer will still choose to block the entry of the spinoff firm and our results would be unchanged.

${ }^{11}$ Along this branch not releasing the employee from the non-compete agreement is strictly dominated and hence
} 


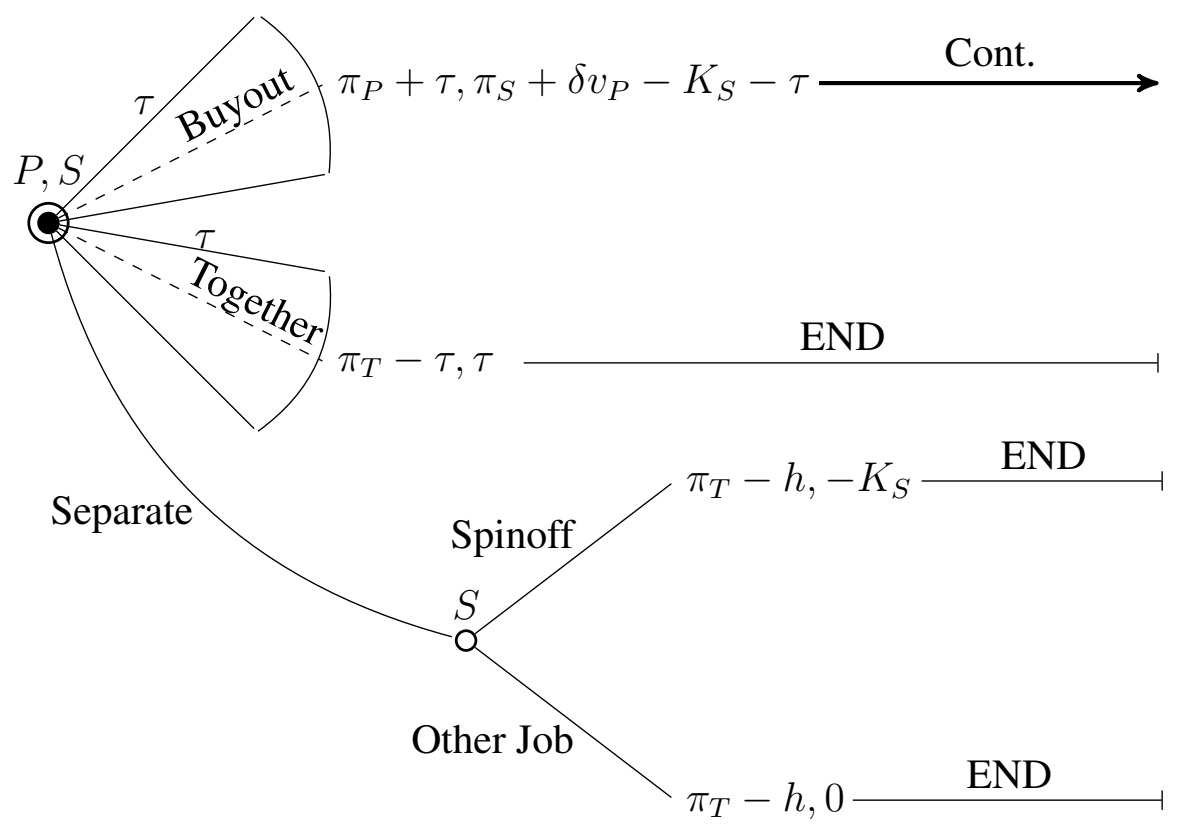

Figure 4.1: One period of the extensive form with non-compete enforcement

period with the same timing and the employee now in the role of employer.

We can quickly see that, unlike in the previous section, there will not exist any Markov perfect equilibrium in which the two parties disagree in every period. They can always agree to stay together and divide a surplus from agreement $h$, making the employer better off by $(1-\lambda) h$ and the employee better off by $\lambda h$ relative to the disagreement point. The candidates for Markov perfect equilibria are therefore an equilibrium in which the employer and employee agree to stay together in period 1 (and would agree to stay together in every subsequent period if the game continued), and an equilibrium in which the employer agrees to release the employee from the non-compete agreement in period 1 and every subsequent period. We will call the former equilibrium a together equilibrium and the latter equilibrium a buyout equilibrium. The reason for the latter name is that, with a threat point of zero, the employee will have to transfer some of the profits from his spinoff firm to his former employer, in effect buying out the non-compete clause in his employment contract.

Considering the buyout equilibrium first, the surplus from agreement is $\pi_{P}+\pi_{S}+\delta v_{B}-K_{S}-$ $\left(\pi_{T}-h\right)$, where $v_{B}$ is the continuation value for the employee and is given by the payoff to the incumbent firm in the buyout equilibrium. We have $v_{B}=\pi_{T}-h+(1-\lambda)\left[\pi_{P}+\pi_{S}+\delta v_{B}-\right.$ omitted from the figure for simplicity. 
$\left.K_{S}-\left(\pi_{T}-h\right)\right]$, or $v_{B}=\left[\lambda\left(\pi_{T}-h\right)+(1-\lambda)\left(\pi_{P}+\pi_{S}-K_{S}\right)\right] /[1-(1-\lambda) \delta]$. Turning to the together equilibrium, the surplus from agreement is $h$, as we have seen. The parties then prefer the buyout equilibrium when $\pi_{P}+\pi_{S}+\delta v_{B}-K_{S}-\left(\pi_{T}-h\right)>h$ or $\pi_{P}+\pi_{S}+\delta v_{B}-K_{S}-\pi_{T}>0$, and prefer the together equilibrium otherwise. This condition reduces to $K_{S}<\pi_{P}+\pi_{S}-(1-$ $\delta) \pi_{T}-\delta \lambda h$. In other words, the buyout equilibrium is the unique Markov perfect equilibrium for $K_{S}<\pi_{P}+\pi_{S}-(1-\delta) \pi_{T}-\delta \lambda h$, and the together equilibrium is the unique Markov perfect equilibrium otherwise.

We have now established

Proposition 4.1. Consider an environment with enforcement of non-compete contracts and no finance constraints. Assume entry of the original firm in period 0. Given $K_{S}<\left(\pi_{P}-\pi_{T}\right)+$ $\pi_{S}+\delta\left(\pi_{T}-\lambda h\right)$, a unique Markov perfect equilibrium exists in which, in period 1 and every subsequent period, the employee buys out his non-compete contract and founds a spinoff firm. Given $K_{S} \geq\left(\pi_{P}-\pi_{T}\right)+\pi_{S}+\delta\left(\pi_{T}-\lambda h\right)$, a unique Markov perfect equilibrium exists in which the employer and employee agree to stay together in period 1 (and would agree to stay together in every subsequent period if the game continued).

Comparing Proposition 4.1 with Proposition 3.1, it follows from $\pi_{T}-h>\pi_{P}$ that enforcement of non-compete contracts actually supports spinoff entry (and does not keep the employer and employee together) for a higher level of spinoff entry cost than non-enforcement of non-compete contracts. This occurs because the employer and employee, when agreeing to release the latter from his non-compete contract so he can found a spinoff firm, are able to collectively extract profits from future spinoff firms.

Using Proposition 4.1, we can again work backwards to the entry decision of the original firm. When the buyout equilibrium obtains, the original firm anticipates earning $\pi_{0}+\delta v_{B}-K_{0}=$ $\pi_{0}+\delta\left[\lambda\left(\pi_{T}-h\right)+(1-\lambda)\left(\pi_{P}+\pi_{S}-K_{S}\right)\right] /[1-(1-\lambda) \delta]-K_{0}$. When the together equilibrium obtains, the original firm anticipates earning $\pi_{0}+\delta\left(\pi_{T}-\lambda h\right)-K_{0}$. We thus have

Proposition 4.2. When the buyout equilibrium obtains, the original firm enters if and only if $\pi_{0}+$ $\delta\left[\lambda\left(\pi_{T}-h\right)+(1-\lambda)\left(\pi_{P}+\pi_{S}-K_{S}\right)\right] /[1-(1-\lambda) \delta]>K_{0}$. When the together equilibrium obtains, the original firm enters if and only if $\pi_{0}+\delta\left(\pi_{T}-\lambda h\right)>K_{0}$.

The same reasoning that leads to Proposition 3.3 then yields 
Proposition 4.3. When the buyout equilibrium obtains, the social optimum is achieved. When the together equilibrium obtains, the social optimum is achieved when $K_{S} \geq \pi_{P}+\pi_{S}-(1-\delta) \pi_{T}$, but not for $\pi_{P}+\pi_{S}-\pi_{T}+\delta\left(\pi_{T}-\lambda h\right) \leq K_{S}<\pi_{P}+\pi_{S}-(1-\delta) \pi_{T}$, when the social optimum would be achieved if there were spinoff entry. When the original firm does not enter and $K_{0}<\pi_{0}+\delta \pi_{T}$ for $K_{S}>\pi_{P}+\pi_{S}-(1-\delta) \pi_{T}$ or $K_{0}<\pi_{0}+\delta\left(\pi_{P}+\pi_{S}-K_{S}\right) /(1-\delta)$ for $K_{S} \leq \pi_{P}+\pi_{S}-(1-\delta) \pi_{T}$, the social optimum is not achieved.

Propositions 4.2 and 4.3 are illustrated in Figure 4.2. A comparison of Figure 4.2 with Figure 3.2 shows that enforcement of non-compete contracts with no finance constraints unambiguously dominates non-enforcement. The combinations of original firm and spinoff entry costs for which the original firm enters and for which the social optimum is achieved without enforcement of non-competes are strict subsets of those respective combinations with enforcement and no finance constraints.

$\triangle$ Buyout Equilibrium $\triangle$ Together Equilibrium Social Optimum achieved

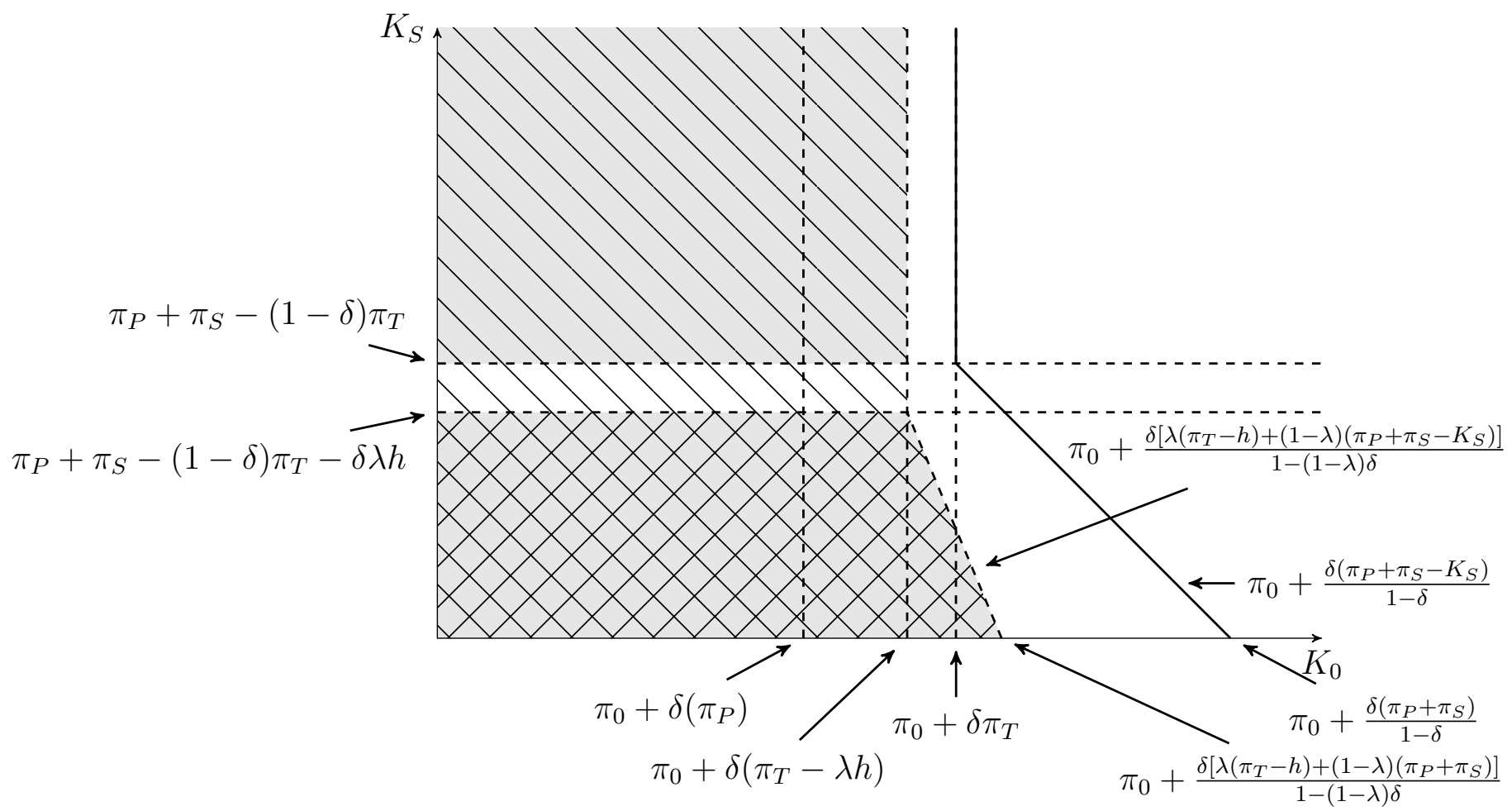

Figure 4.2: Equilibria and social optimum with enforcement of non-compete contracts 
We conclude this section by noting that, if the employer has all the bargaining power in negotiations with the employee, the social optimum is achieved for all combinations of original firm and spinoff entry costs.

Corollary. Consider an environment with enforcement of non-compete contracts and no finance constraints. If $\lambda=0$, the social optimum is achieved for all $\left(K_{0}, K_{S}\right)$.

Proof. From Proposition 4.3, we see that the range of $K_{S}$ for which the social optimum is not achieved is eliminated when $\lambda=0$, i.e., the partition of the values of $K_{S}$ into those where the buyout or together equilibrium obtains is now socially optimal. From Propositions 4.2 and 4.3, we see that when $\lambda=0$ the original firm always enters when it is socially optimal for it to do so, i.e., the cases where the social optimum is not achieved because the original firm does not enter have been eliminated.

Once it has all the bargaining power and is able to enforce non-compete contracts with its employees, it is to be expected that the original firm is able to capture all profits generated by the first-generation spinoff. It may be surprising, however, that the original firm is able to capture all profits generated by the infinite stream of future spinoffs, given that these spinoffs are not parties to the negotiations between the original firm and its employee. The key is that these firms are brought into the negotiations implicitly through the continuation value of the employee in a Markov perfect equilibrium. The result is analogous to "Ricardian equivalence" in an overlapping generations model with bequests (Barro 1974), that is, overlapping generations of consumers in such a model can generate behavior equivalent to that of an infinitely-lived consumer.

\section{Equilibria and social welfare with non-compete enforcement and employee finance constraints}

Enforcement of non-compete contracts supports entry of both original firms and spinoff firms when high entry costs prevent their entry without such enforcement. The key to these improved outcomes is the ability of employers to extract transfers from employee-entrepreneurs to release them from their non-compete agreements. Of the various equilibria we have considered in the previous two sections, only in the buyout equilibrium are payments made by employees to employers. 
Unlike the sunk cost of entry $K_{S}$, which can be paid in "sweat equity,"12 it is reasonable to assume that the contract buyout must be made in cash. Paying the employer by working for free after informing the employer of his intention to resign is likely to cause the employee to forfeit his business opportunity, leaving him worse off (or at least no better off) than if he agreed to stay together with the employer.

There are several barriers that limit the ability of the employee to make a monetary transfer to his employer. ${ }^{13}$ First, workers typically do not have the resources to internally (out of pocket) finance a large payment. Second, external financing generally is limited due to informational asymmetries between the employee and outside lending institutions. If profits from the future spinoff are not verifiable, the (former) employee can hide his income and declare that his new firm has failed. Similarly, promises by the employee to pay his employer in the future, after earning the profits from his new firm, may not be enforceable.

In this section we will explore the implications of the assumption that employees in our model are finance constrained. The finance-constraint assumption is consistent with the stories that workers tell. ${ }^{14}$ Industry observers with whom we have spoken agree that buyouts of non-compete contracts are rare except at the highest level, such as star CEOs. Unfortunately, we are unaware of any survey data on the subject.

It is easily shown that a worker finance constraint would never be binding and would not affect our analysis when non-compete agreements are not enforced. We therefore confine our analysis in this section to the case where non-compete agreements are enforced. In this case, as we saw in the previous section, the employer (incumbent) has the power to unilaterally compel disagreement and obtain $\pi_{T}-h$. Since the incumbent earns $\pi_{P}$ when an employee spinoff enters, the employee will have to transfer at least $\pi_{T}-h-\pi_{P}$ to get the employer to release him from his non-compete contract. ${ }^{15}$ If the employee's wealth is smaller than that amount, he will do better to stay together

\footnotetext{
${ }^{12}$ Djankov, La Porta, Lopez de Silanes, and Shleifer (2002) find that the monetary cost of satisfying government regulatory requirements to establish a new business in the United States is less than one-half of one percent of per capita GDP.

${ }^{13}$ Some of the discussion in this paragraph and the next is based on Rauch and Watson (2015).

${ }^{14}$ Workers we have interviewed do not consider borrowing to buy out their non-compete contracts to be a viable option. Several workers with a major international market research firm, disgruntled with a change in management following a merger, told us they thought they could better serve their clients by setting up their own firms but felt trapped by their non-competes and lacked the cash to buy them out.

${ }^{15}$ It is easy to show that the employee always pays at least $\pi_{T}-h-\pi_{P}$ to the employer in the buyout equilibrium. The transfer from the employee to the employer in the buyout equilibrium equals the difference between the incumbent firm's payoff $v_{B}$ and $\pi_{P}$, which is given by $\left[\lambda\left(\pi_{T}-h\right)+(1-\lambda)\left(\pi_{P}+\pi_{S}-K_{S}\right)\right] /[1-(1-\lambda) \delta]-\pi_{P}$. This expression is decreasing in $\lambda$ and in $K_{S}$, so it reaches its minimum when $\lambda=1$ and $K_{S}=\left(\pi_{P}-\pi_{T}\right)+\pi_{S}+\delta\left(\pi_{T}-\lambda h\right)$ (at this
} 
with the employer and earn $\lambda h$ instead of zero. We assume that an incumbent firm has an established line of credit and hence does not encounter a finance constraint in making this payment to the worker immediately upon conclusion of negotiations.

It follows that when an employee with little wealth cannot borrow against future income, the buyout equilibrium of the previous section ceases to exist, and the together equilibrium of the previous section becomes the unique Markov perfect equilibrium regardless of the value of $K_{S}$. We have thus established

Proposition 5.1. Consider an environment with enforcement of non-compete contracts in which the employee cannot borrow against future income. Assume entry of the original firm in period 0. If the employee has wealth $<\pi_{T}-h-\pi_{P}$, then for any value of $K_{S}$ a unique Markov perfect equilibrium exists in which the employer and employee agree to stay together in period 1 (and would agree to stay together in every subsequent period if the game continued).

From Proposition 5.1 it follows that, when employees are finance constrained, an original firm that enters can always anticipate earning $\pi_{0}+\delta\left(\pi_{T}-\lambda h\right)-K_{0}$. We thus have

Proposition 5.2. Consider an environment with enforcement of non-compete contracts in which the employee cannot borrow against future income. If the employee has wealth $<\pi_{T}-h-\pi_{P}$, the original firm enters if and only if $\pi_{0}+\delta\left(\pi_{T}-\lambda h\right)>K_{0}$.

The same reasoning that led to Propositions 3.3 and 4.3 then yields

Proposition 5.3. Consider an environment with enforcement of non-compete contracts in which the employee cannot borrow against future income. If the employee has wealth $<\pi_{T}-h-\pi_{P}$, the social optimum is achieved only when $K_{0}<\pi_{0}+\delta\left(\pi_{T}-\lambda h\right)$ and $K_{S} \geq \pi_{P}+\pi_{S}-(1-\delta) \pi_{T}$.

Since finance constraints prevent employee spinoffs, the social optimum can only be achieved when the original firm enters and spinoffs are not socially profitable.

Propositions 5.2 and 5.3 are illustrated in Figure 5. The interesting comparison is between Figure 5 and Figure 3.2, both of which illustrate outcomes that are weakly inferior to those obtained when non-compete contracts are enforced without finance constraints. If we were to restrict our attention to consideration of original firms with $K_{0}<\pi_{0}+\delta \pi_{P}$, we could state that the combinations

value of $K_{S}$ the parties switch from the buyout to the together equilibrium). Plugging these values into the expression yields $\pi_{T}-h-\pi_{P}$. 
$X_{X}$ Buyout Equilibrium $\searrow$ Together Equilibrium $\square$ Social Optimum achieved

$\pi_{P}+\pi_{S}-(1-\delta) \pi_{T}$

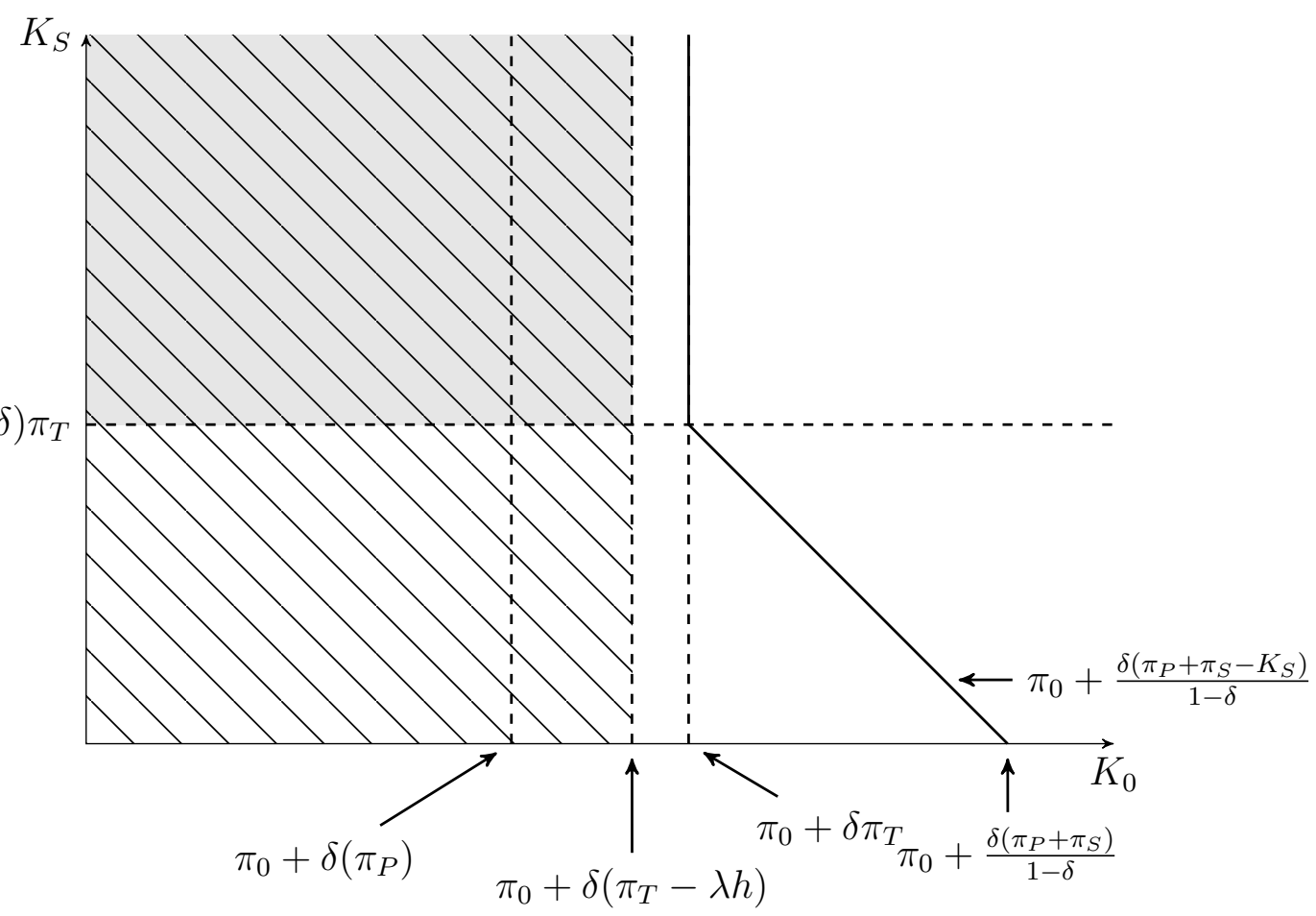

Figure 5: Equilibria and social optimum with enforcement of non-compete contracts and finance constraints

of original firm and spinoff entry costs for which the social optimum is achieved with enforcement of non-compete contracts and finance constraints is a strict subset of those combinations for which the social optimum is achieved without enforcement of non-competes. This occurs because lack of enforcement allows profitable spinoff entry to follow entry of a profitable original firm. We would then have an example of the theory of the second best: eliminating one distortion (inability to enforce non-compete contracts) in the presence of another (finance constraints) makes society worse off. However, because $\pi_{T}-\lambda h>\pi_{P}$, when $K_{S}$ is low some marginally profitable original firms enter with enforcement of non-compete contracts and finance constraints that do not enter without enforcement of non-compete contracts. Thus we cannot say that non-enforcement weakly dominates enforcement with finance constraints for all combinations of original firm and spinoff entry costs. 


\section{Conclusions}

As new data reveal the ubiquity of employee spinoffs as a mode of entry, the importance of understanding the impact of policy on entry of both parent and spinoff firms becomes increasingly evident. Since spinoffs can and do become parents themselves, we have taken a dynastic (overlapping generations) modeling approach to this investigation, focusing on enforcement of noncompete agreements as the key policy specific to spinoff entry. We find that, without finance constraints, enforcement of non-compete agreements unambiguously improves social welfare outcomes. Indeed, enforcement not only encourages original (parent) firm entry but even stimulates spinoff entry, because each spinoff generation is able to capture some of the profit of the next generation when the entrepreneurial employee is forced to buy out his non-compete contact. However, if employees are unable to buy out their non-compete contracts due to finance constraints, enforcement of these agreements shuts down entry of socially profitable spinoff firms. Non-enforcement sacrifices entry of original firms that would be marginally profitable in the absence of employee spinoffs, but otherwise clearly improves social welfare outcomes over enforcement in the presence of finance constraints, by allowing entry of socially profitable spinoff firms.

Since enforcement of non-competes increases the rate of spinoffs from original firms without finance constraints but non-enforcement of non-competes increases the spinoff rate with finance constraints, the impact of non-compete enforcement on spinoff entrepreneurship can provide indirect evidence regarding the relevance of finance constraints. We cannot rely on evidence of whether finance constraints affect business startups in general, ${ }^{16}$ because the typical business startup does not require buying out a non-compete contract. Lenders may be more reluctant to lend for this purpose since there are obviously no tangible assets to collateralize such a loan. Unfortunately, evidence on the impact of non-compete enforcement on spinoff entrepreneurship is too weak at this point to support any conclusion. ${ }^{17}$ In the legal services industry, where the norm that clients have the right to choose who represents them has always prohibited enforcement of non-compete contracts, anec-

\footnotetext{
${ }^{16}$ In any case, influential studies using U.S. data support both positions: for example, Evans and Jovanovic (1989) provide evidence that finance constraints matter and Hurst and Lusardi (2004) provide evidence they do not.

${ }^{17}$ The natural experiment described by Marx, Strumsky, and Fleming (2009), in which Michigan inadvertently switched from non-enforcement to enforcement of non-competes, could in principle be used to generate stronger evidence. The difficulty is in distinguishing employee spinoffs from other startups, which is especially important given that our model predicts opposite effects of the switch to enforcement on spinoff and original firm startups in the presence of finance constraints. Unfortunately the quality of the data available for this purpose for the United States has not yet caught up with the quality of the data available for Denmark (Eriksson and Kuhn 2006) or Brazil (Muendler, Rauch, and Tocoian 2012), but may do so in the near future.
} 
dotal evidence on the frequency of "grabbing and leaving" supports the view that non-enforcement promotes employee spinoffs (Rebitzer and Taylor 2007), but no systematic comparison of legal services with other business and professional services has been done to our knowledge.

If, as we suspect, finance constraints do indeed prevent employees from buying out their noncompete agreements, is the appropriate policy response to stop enforcing non-competes, as in California? The wide variation in non-compete enforcement policy across U.S. states provides an opportunity for relatively low-cost experiments. For example, the U.S. Small Business Administration could start a program of lending targeted at non-compete buyouts in a U.S. state where non-competes are vigorously enforced. Given our result that enforcement of non-competes dominates non-enforcement in the absence of finance constraints, an experiment along these lines seems warranted. 


\section{References}

Acs, Z. J., E. L. Glaeser, R. E. Litan, L. Fleming, S. J. Goetz, W. R. Kerr, S. Klepper, S. S. Rosenthal, O. Sorenson, and W. C. Strange (2008): "Entrepreneurship and urban success: toward a policy consensus," Ewing Marion Kauffman Foundation.

BACCARA, M., AND R. RAZIN (2009): "Innovation and Corporate Conservatism,” NYU Stern School of Business Working Paper.

BArro, R. J. (1974): “Are Government Bonds Net Wealth?” The Journal of Political Economy, 82(6), $1095-1117$.

Bessen, J., AND E. MASKin (2009): "Sequential Innovation, Patents, and Imitation," The RAND Journal of Economics, 40(4), 611-635.

Djankov, S., R. La Porta, F. Lopez de Silanes, And A. Shleifer (2002): "The Regulation of Entry," Quarterly Journal of Economics, 117(1), 1-37.

Dunne, T., M. J. Roberts, And L. Samuelson (1988): "Patterns of Firm Entry and Exit in U.S. Manufacturing Industries," RAND Journal of Economics, 19(4), 495-515.

ERIKSSON, T., AND J. M. Kuhn (2006): "Firm Spin-Offs in Denmark 1981-2000: Patterns of Entry and Exit," International Journal of Industrial Organization, 24(5), 1021-1040.

Evans, D., AND B. Jovanovic (1989): "An Estimated Model of Entrepreneurial Choice under Liquidity Constraints," Journal of Political Economy, 97, 808-827.

Fallick, B., C. A. Fleishman, And J. B. Rebitzer (2006): "Job-Hopping in Silicon Valley: Some Evidence Concerning the Midro Foundations of a High-technology Cluster," Review of Economics and Statistics, 80(3), 472-481.

FRANCO, A. M., AND D. FILSON (2006): "Spin-Outs: Knowledge Diffusion through Employee Mobility," RAND Journal of Economics, 37(4), 841-860.

Franco, A. M., AND M. F. Mitchell (2008): "Covenants Not to Compete, Labor Mobility, and Industry Dynamics," Journal of Economics and Managemnet Strategy, 17, 581-606.

Garmaise, M. J. (2011): "Ties That Truly Bind: Noncompetition Agreements, Executive Compensation, and Firm Investment," Journal of Law, Economics, and Organization, 27, 376-425.

GiLson, R. J. (1999): “The Legal Infrastructure of High Technology Industrial Districts: Silicon Valley, Route 128, and Covenants Not To Compete," New York University Law Review, 74(3), 575-629.

HURST, E., AND A. LUSARDI (2004): "Liquidity constraints, household wealth, and entrepreneurship," Journal of Political Economy, 112(2), 319-347.

HvidE, H. K. (2009): “The Quality of Entrepreneurs,” Economic Journal, 119(539), 1010-1035.

KlepPer, S., AND S. SleEPer (2005): "Entry by Spinoffs," Management Science, 51(8), 1291-1306.

KRÄKEL, M., AND D. SliwKA (2009): "Should You Allow Your Employee to Become Your Competitor? On Noncompete Agreements in Employment Contracts," International Economic Review, 50, 117-141. 
Laffont, J.-J., And D. Martimort (2001): The Theory of Incentives: The Principal-Agent Model. Princeton University Press.

Marx, M., D. Strumsky, And L. Fleming (2009): "Mobility, Skills, and the Michigan Non-Compete Experiment," Management Science, 55, 875-889.

Motta, M., And T. Roende (2002): “Trade Secret Laws, Labour Mobility, and Innovations,” Discussion Paper No. 3615, Centre for Economic Policy Research.

Muendler, M.-A., AND J. E. RAUCH (2014): "What Do Employee Spinoffs Learn from Their Parents? Evidence from International Trade," University of California, San Diego, unpublished manuscript.

MuendleR, M.-A., J. E. Rauch, And O. Tocoian (2012): "Employee Spinoffs and Other Entrants: Stylized Facts from Brazil," International Journal of Industrial Organization, 30(5), 447-458.

PhilliPS, D. J. (2002): "A Genealogical Approach to Organizational Life or Chances: The Parent-progeny Transfer Among Silicon Valley Law Firms, 1946-1996," Administrative Science Quarterly, 47(3), 474506.

RAUCH, J. E., AND J. WATSON (2015): “Client-Based Entrepreneurship,” Journal of Law, Economics, and Organization, 31(1), 30-60.

REBITZER, J. B., AND L. J. TAYLOR (2007): "When Knowledge is an Asset: Explaining the Organizational Structure of Large Law Firms," Journal of Labor Economics, 25, 201-229.

SHIEH, G. (1992): “Boss” island: The subcontracting network and microentrepreneurship in Taiwan's development. Peter Lang, New York.

Watson, J. (2013): Strategy: An Introduction to Game Theory. W. W. Norton and Company, New York, third ed. 


\section{Appendix: Proof of Proposition 3.1}

Proof. Given the stationary environment, without enforcement of non-compete contracts only three Markov perfect equilibria are possible. In the no-spinoff equilibrium, the employer and employee stay together in period 1 , and would agree to stay together in every subsequent period if the game continued. In the spinoff equilibrium, the employer and employee separate in period 1 and the employee founds a spinoff firm; this repeats in every subsequent period. In the other possible equilibrium, the employer and employee separate in period 1 and the employee takes a job with another firm; this would occur in every subsequent period if the game continued. Proposition 3.1 states that, following entry of the original firm in period 0 , the spinoff equilibrium is the unique Markov perfect equilibrium when $K_{S}<\left(\pi_{P}-\pi_{T}\right)+\pi_{S}+\delta \pi_{P}$ and the no-spinoff equilibrium is the unique Markov perfect equilibrium when $K_{S} \geq\left(\pi_{P}-\pi_{T}\right)+\pi_{S}+\delta \pi_{P}$.

First consider the spinoff equilibrium. In the text, it was shown that in the case $K_{S}<\pi_{S}+\delta \pi_{P}$, the threat point of the employee is $\pi_{S}+\delta \pi_{P}-K_{S}$, and the threat point of the employer is $\pi_{P}$. If the two parties stay together, their combined payoff is $\pi_{T}$. Let us provisionally restrict our attention to the case $K_{S}<\pi_{S}+\delta \pi_{P}$. In this case, the two parties fail to agree (separate) if $\pi_{P}+\pi_{S}+\delta \pi_{P}-K_{S}>\pi_{T}$, or $K_{S}<\left(\pi_{P}-\pi_{T}\right)+\pi_{S}+\delta \pi_{P}<\pi_{S}+\delta \pi_{P}$, since $\pi_{T}>\pi_{P}$. This establishes the existence of the spinoff equilibrium given $K_{S}<\left(\pi_{P}-\pi_{T}\right)+\pi_{S}+\delta \pi_{P}$.

Next consider the no-spinoff equilibrium. In the text, it was shown that if the employee founds a spinoff firm when the parties separate, the threat point of the employer is $\pi_{P}$, and the threat point of the employee is $\pi_{S}+\delta v_{N S}-K_{S}$, where $v_{N S}=\left[\lambda \pi_{P}+(1-\lambda)\left(\pi_{T}-\pi_{S}+K_{S}\right)\right] /[1+(1-\lambda) \delta]$. If the employee takes another job when the parties separate, his threat point is zero, and the threat point of the employer is $\pi_{T}-h$.

It is easily seen that $\pi_{S}+\delta v_{N S}-K_{S}$ decreases with $K_{S}$. It follows that, for $K_{S}$ high enough, the employee's best action after separation is to take another job. For $K_{S}$ in this range, a Markov perfect equilibrium in which the two parties always agree to stay together clearly exists: staying together yields a joint payoff of $\pi_{T}$ and separation yields a joint payoff of $\pi_{T}-h$. Does this equilibrium exist for lower values of $K_{S}$, for which the employee's best action after separation is to found a spinoff? The employee founds a spinoff after separation if $\pi_{S}+\delta v_{N S}-K_{S}>0$, or $K_{S}<\pi_{S}+\delta\left[\pi_{T}-\lambda\left(\pi_{T}-\pi_{P}\right)\right]$. The surplus from agreement in this case is $\pi_{T}-\pi_{P}-\pi_{S}-\delta v_{N S}+K_{S}$, which is nonnegative if $K_{S} \geq(1+\delta) \pi_{P}+\pi_{S}-\pi_{T}$. Simple manipulation then shows that $(1+\delta) \pi_{P}+\pi_{S}-\pi_{T}<\pi_{S}+\delta\left[\pi_{T}-\lambda\left(\pi_{T}-\pi_{P}\right)\right]$ follows from $\pi_{T}>\pi_{P}$. We conclude that a Markov perfect equilibrium exists in which the employer and employee agree to stay together for all $K_{S} \geq(1+\delta) \pi_{P}+\pi_{S}-\pi_{T} .{ }^{18}$ This establishes the existence of the no-spinoff equilibrium given $K_{S} \geq\left(\pi_{P}-\pi_{T}\right)+\pi_{S}+\delta \pi_{P}$.

\footnotetext{
${ }^{18}$ Suppose that, when negotiating with the employer, the employee could commit to a course of action upon separation. That is, the employee can choose between (a) separate and found a spinoff firm and (b) separate and take another job. The employee is then indifferent between (a) and (b) when $\pi_{S}+\delta v_{N S}-K_{S}+\lambda\left(\pi_{T}-\pi_{P}-\right.$ $\left.\pi_{S}-\delta v_{N S}+K_{S}\right)=\lambda h$, or $K_{S}=\pi_{S}+\delta \pi_{T}+\lambda\left[\left(\pi_{T}-\pi_{P}\right)-h(1+\delta(1-\lambda))\right] /(1-\lambda)$. Simple manipulation shows that $(1+\delta) \pi_{P}+\pi_{S}-\pi_{T}<\pi_{S}+\delta \pi_{T}+\lambda\left[\left(\pi_{T}-\pi_{P}\right)-h(1+\delta(1-\lambda))\right] /(1-\lambda)$ reduces to $\pi_{P}<\pi_{T}-\lambda h$, which follows from $\pi_{T}-h>\pi_{P}$. Hence the range of $K_{S}$ for which the no-spinoff equilibrium obtains is unchanged in this commitment case. However, examining the condition for indifference between (a) and (b), we can see that $\pi_{T}-h>\pi_{P}$ also implies that the employee chooses to take another job rather than found a spinoff for a higher value of $K_{S}$ when commitment is possible than when it is not possible. Thus, in the range $\pi_{S}+\delta\left[\pi_{T}-\lambda\left(\pi_{T}-\pi_{P}\right)\right] \leq K_{S}<\pi_{S}+\delta \pi_{T}+\lambda\left[\left(\pi_{T}-\pi_{P}\right)-h(1+\delta(1-\lambda))\right] /(1-\lambda)$, the ability to commit to a course of action makes the employee better off (and the employer worse off).
} 
Having established existence of the spinoff and no-spinoff equilibria in the specified, mutually exclusive and exhaustive ranges for $K_{S}$, we complete the proof of Proposition 3.1 by showing for each of these equilibria that existence of either of the other two equilibria in the specified range for $K_{S}$ leads to a contradiction.

We first prove that the spinoff equilibrium is the unique equilibrium when $K_{S}<\left(\pi_{P}-\pi_{T}\right)+\pi_{S}+\delta \pi_{P}$. Consider the equilibrium in which the employee takes a job with another firm. It is sequentially rational for the employee to take another job rather than found a spinoff firm after separation only if $K_{S} \geq \pi_{S}+\delta \pi_{P}$. But this contradicts the parameter values for the spinoff equilibrium, since $K_{S}<\left(\pi_{P}-\pi_{T}\right)+\pi_{S}+\delta \pi_{P}<$ $\pi_{S}+\delta \pi_{P}$. Now consider the equilibrium in which the employer and employee agree to stay together. Since $\left(\pi_{P}-\pi_{T}\right)+\pi_{S}+\delta \pi_{P}<\pi_{S}+\delta\left[\pi_{T}-\lambda\left(\pi_{T}-\pi_{P}\right)\right]$, the threat point for their negotiations is determined by the employee founding a spinoff firm. It follows that they would divide the surplus $\pi_{T}-\pi_{P}-\pi_{S}-\delta v_{N S}+K_{S}=\left[K_{S}+\pi_{T}-(1+\delta) \pi_{P}-\pi_{S}\right] /[1+(1-\lambda) \delta]$. But simple manipulation shows this to be negative if $K_{S}<\left(\pi_{P}-\pi_{T}\right)+\pi_{S}+\delta \pi_{P}$, hence agreement to stay together (the no-spinoff equilibrium) leads to a contradiction for the parameter values under which the spinoff equilibrium obtains.

We next prove that the no-spinoff equilibrium is the unique equilibrium when $K_{S} \geq\left(\pi_{P}-\pi_{T}\right)+\pi_{S}+$ $\delta \pi_{P}$. Under these parameter values, if the parties always disagree the employee will found a spinoff firm if $K_{S}<\pi_{S}+\delta \pi_{P}$, and will take another job otherwise. In the former case the spinoff equilibrium obtains, and in the latter case the equilibrium in which the employee takes a job with another firm obtains. In the spinoff equilibrium, the joint payoff to the two parties is $\pi_{P}+\pi_{S}+\delta \pi_{P}-K_{S}$. Were the two parties to agree, their joint payoff would be $\pi_{T}$. It follows immediately from $K_{S} \geq\left(\pi_{P}-\pi_{T}\right)+\pi_{S}+\delta \pi_{P}$ that there is a nonnegative surplus from agreement, hence existence of the spinoff equilibrium leads to a contradiction for these parameter values. If the equilibrium in which the employee takes another job obtains, the joint payoff to the two parties is $\pi_{T}-h$. Were the two parties to agree, their joint payoff would again be $\pi_{T}$. There is a positive surplus from agreement given by $h$, hence existence of an equilibrium in which the two parties disagree (separate) and the employee takes a job with another firm leads to a contradiction. 